\title{
ПРОТЕСТНЫЕ НАСТРОЕНИЯ В РЕСПУБЛИКЕ ДАГЕСТАН (ПО ДАННЫМ СОЦИОЛОГИЧЕСКОГО ОПРОСА)
}

\author{
(c) 2018 Хаджалова Хадижат Магомедовна \\ доктор экономических наук, доцент, ведущий научный сотрудник \\ Институт социально-экономических исследований Дагестанского научного центра РАН \\ профессор кафедры «Управление проектами и программами» \\ Дагестанский государственный университет народного хозяйства \\ 367030, Россия, Республика Дагестан, г. Махачкала, улица Ярагского, д. 75 \\ E-mail: chaha@mail.ru \\ (c) 2018 Абдулманапов Салихбек Габибуллаевич \\ доктор экономических наук, профессор \\ директор НИИ «Управления, экономики, политики и социологии» \\ Дагестанский государственный университет народного хозяйства \\ 367030, Россия, Республика Дагестан, г. Махачкала, улица Ярагского, д. 75 \\ E-mail: salih@mail.ru
}

Статья посвящена выявлению протестных настроений жителей республики в 2017 г. Проведено сопоставление с аналогичным авторским исследованием 2007 г. Выявлены причины роста напряженности в обществе, факторы протестной активности населения, а также закономерности, определяющие их интенсивность и характер проявления. Результаты оценки социальной напряженности в Республике Дагестан и уровня протестной активности свидетельствуют об обеспокоенности и недовольстве людей в целом социально-экономической ситуацией в регионе.

Ключевые слова: протестная активность, протестные настроения, протестный потенциал, Республика Дагестан.

Введение. В настоящее время современное российское общество в своем развитии переживает период кризиса, который активно проявляется в росте социальной напряженности в различных сферах общественной жизни. Социальный протест является определенным критерием социальной напряженности. Исследование сущности социального протеста и форм его проявления является одним из наиболее важных аспектов изучения и прогнозирования развития общества и предупреждения социальных конфликтов. Возникновение социального протеста как формы выражения неудовлетворенности населения уровнем и качеством жизни является угрозой функционирования экономической системы, способной породить масштабный экономический кризис.

Основная часть. С целью исследования протестных настроений авторами в 2017 г. проведен опрос «Потенциал протеста». Опрос проводился среди 200 респондентов жителей Республики Дагестан, которые отвечали на вопросы: есть ли потенциал протеста в регионе, с чем он связан и к каким последствиям могут привести те или иные действия протестующих. Подобное исследование было проведено в 2007 г., его и будем использовать как базовый период (выборка 500 человек) [2].

В опросе приняли участие как сельское, так и городское население республики. Причем, городское (в 2007 г. $-66,8 \%$ и в 2017 г. $-66,2 \%$ ) в три раза превышало сельское вследствие того, что жители сел очень тяжело «идут на контакт». Основная часть опрощенных - женщины (в 2007 г. - 59,6\%, в 2017 г.- 56,3\%). Основной возраст респондентов приходился на 18-30 лет (свыше 40\%) и 31-55 лет (около 40\%). Большинство участников опроса - это люди с высшим (в среднем 46\%) и со средне специальным (около $20 \%)$ образованием.

Оценивая современную ситуацию в соответствии с вышеотмеченными характеристиками, следует отметить, что большинство жителей Дагестана испытывают неудовлетворенность своим положением в обществе, материальными условиями жизни, не доверяют общественным структурам и политическим институтам. 
Рассматривая политическую ситуацию 2017 г. в Республике Дагестан, свыше 50\% опрошенных расценивают ее как напряженную, а $26,4 \%$ - критическую и даже взрывоопасную (см. рисунок 1), притом, что в 2007 г. эта цифра составляла $8,4 \%$.

Также в 2017 г. вдвое сократилась доля лиц, расценивающих политическую ситуацию в республике как «спокойная» (в 2017 г.- 14,0\%, а в 2007 г.- 25,2\%) При этом жители региона не надеются на какое-либо улучшение ситуации. Если в 2007 г. 57,4\% населения надеялось на какое-либо улучшение политической обстановки в республике, то в 2017 г. доля сократилась до $16,4 \%$, и обратная ситуация наблюдается с теми, кто надеялся на какое-либо ухудшение политической ситуации. Их доля увеличилась с 17,8\% в 2007 г. до 56,1\% в 2017 г. Это, как правило, является следствием недоверия деятельности Главы Республики Дагестан. Если в 2007 г.- 21,2\% «полностью и в основном не одобряли» деятельность Главы Республики Дагестан», то к 2017 г. их доля удвоилась $(43,7 \%)$. Лишь $1 / 5$ часть респондентов постоянна в своем числе и «полностью и в основном» одобряют его деятельность.

По мнению респондентов руководителей республики должно заботить, прежде всего, материальное положение населения (32,2\% опрошенных в 2017 г.) порядок в республике $(32,1 \%)$ и экономическое положение в республике (26,1\%). Но между тем большая часть населения (48,0\% в 2007 г. и 50,4\% в 2017 г.) не надеялись на улучшение благосостояния своей семьи ни через полгода, ни через год (41,2\% в 2017 г). В 2007 г. $27,5 \%$ населения считает, что «богатые становят- ся богаче, а бедные беднее», а в 2017 г. их число увеличилось еще на 7,7\%. Четверть населения (22,3\% в 2007 г. и 29,9\% в 2017 г.) считают, что «людям у власти нет дела до меня».

Налицо полное недоверие к различным общественным структурам и политическим институтам. Наибольшее доверие отдано мечети (25,9\% респондентов в 2007 г. и 35,4\% в 2017 г.). Между тем, свыше 15\% в 2017 г. не доверяют ни одной общественной структуре. Живя в Дагестане не чувствуют себя в безопасности в 2007 г. 52\% населения, а в 2017 г. их доля увеличилась до 65,1\%. И если в 2007 г. всего 32\% респондентов считали жизнь в Дагестане безопасной, то за два года их доля заметно снизилась и составила в 2017 г. - 20,7\%.

Среднемесячный фактический душевой доход у 54,6\% семей в 2007 г. доставлял до 3000 руб. В 2017 г. их доля сократилась до 42,4\%. С 2007 г. по 2017 г. увеличилась доля семей, получающих доход 3000-5000 в среднем на одного человека. Даже это обстоятельство не помешало 65-70\% респондентам в указанные годы расценить материальное положение своих семьи как «семей среднего достатка» и «денег достаточно лишь на необходимые продукты и одежду». И при этом 41,4\% респондентов в 2017 г. считают, что для нормальной жизни их семей, доход на одного члена их семей должен составлять 10-20 тыс. руб., а в 2007 г. для основной массы опрашиваемых (36,4\%) была указана сумма от 5-10 тыс. руб. Такие массовые стихийные формы воздействия на политику властей принято называть национально-социальным протестом.

Возможность проведения массовых проте-

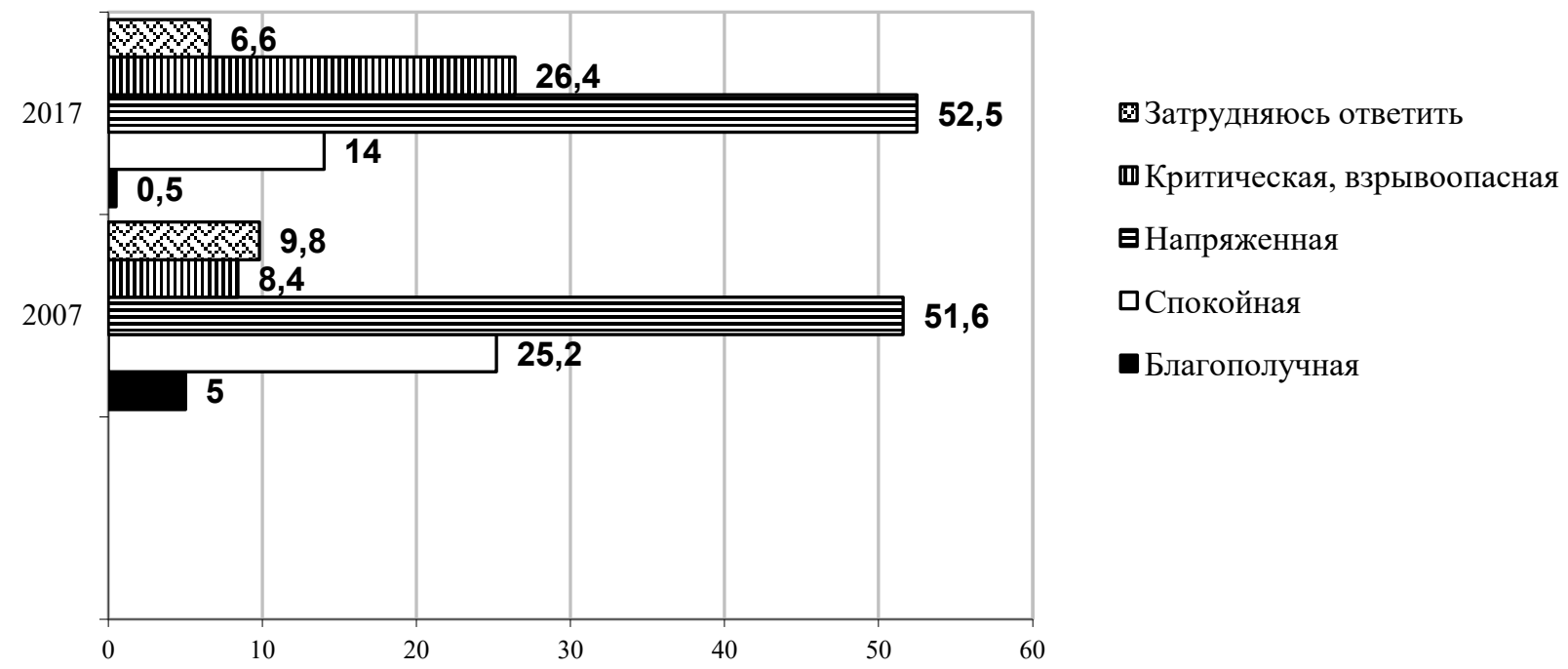

Puc. 1. Оценка респондентами политической обстановки в регионе Составлено автором по результатам проведенного исследования и исследования 2007 г. [2] 
стов против ухудшения жизненного уровня поддержали в 2007 г. - 32,\% населения, а в 2017 г.$22,4 \%$. Эта цифра сократилась почти в 2 раза по отношению к 2007 г. (см. табл. 1).

Теоретическую возможность участия в акции протеста признали в 2017 г. 22,4\% опрошенных, допуская тем самым возможность массовых акций протеста, поводом для которых может стать снижение уровня жизни населения, неправильные действия или бездействие власти. В 2017 г. результат социального протеста уменьшился по сравнению с 2007 г. в 1,6 раза. Свыше половины респондентов (75,1\% - в 2017 г. и 54,6\% - в 2007 г.) высказались против личного участия в каких-либо актах протеста.

Потенциальную склонность к протесту в наибольшей степени проявляют сельские жите- ли республики (табл. 2).

Несмотря на снижение показателей протестной активности с 30,4\% в 2007 г. до 15,3\% - в 2017 г. социальная напряженность, по-прежнему, остается довольно высокой вследствие низкого уровня жизни сельских жителей по сравнению городскими. Городские жители проявляют меньшую склонность к участию в акциях протеста.

В 2017 г. как и в 2007 г., среди жителей республики, идентифицирующих себя с «малообеспеченными и бедными», склонных к проявлению протестных настроений составляло большинство (в 2007 г.- 38,6\%, в 2017 г.- 33,7\%). Существенное снижение наблюдается среди людей «среднего достатка и богатых»: за 10 лет протестный потенциал снизился с 33,7\% в 2007 г. до

Таблица 1. Ответы респондентов на вопрос: «Как Вы считаете, могут ли состояться в вашем городе (районе) массовые выступления против роста цен и падения уровня жизни населения?»

\begin{tabular}{|c|c|c|}
\hline Варианты & 2007 г. & 2017 г. \\
\hline Да, и скорее да, чем нет & 36,8 & 22,4 \\
\hline $\begin{array}{l}\text { в том числе: «Вы лично примете участие в массовых высту- } \\
\text { плениях против роста цен и падения уровня жизни?» } \\
\text { - да } \\
\text { - нет } \\
\text { - затрудняюсь ответить }\end{array}$ & $\begin{array}{l}30,4 \\
54,6 \\
16,2\end{array}$ & $\begin{array}{c}15,3 \\
75,1 \\
9,6\end{array}$ \\
\hline Нет, и скорее нет, чем да & 49,2 & 50,9 \\
\hline Затрудняюсь ответить & 15,5 & 26,7 \\
\hline Итого & 100,0 & 100,0 \\
\hline
\end{tabular}

Примечание: Потенциал протеста составляют респонденты, ответившие «Да»на вопрос: Примите ли Вы личное участие в массовых выступлениях против роста цен и падения уровня жизни»?

Составлено автором по результатам проведенного исследования и исследования 2007 г. [2]

Таблица 2. Динамика потенциала протеста респондентов (в \%)

\begin{tabular}{|l|c|c|}
\hline \multicolumn{1}{|c|}{ Территории } & 2007 г. & 2017 г. \\
\hline По республике & 30,4 & 15,3 \\
\hline По городам & 27,2 & 9,4 \\
\hline По районам & 36,1 & 21,2 \\
\hline
\end{tabular}

Составлено автором по результатам проведенного исследования и исследования 2007 г. [2]

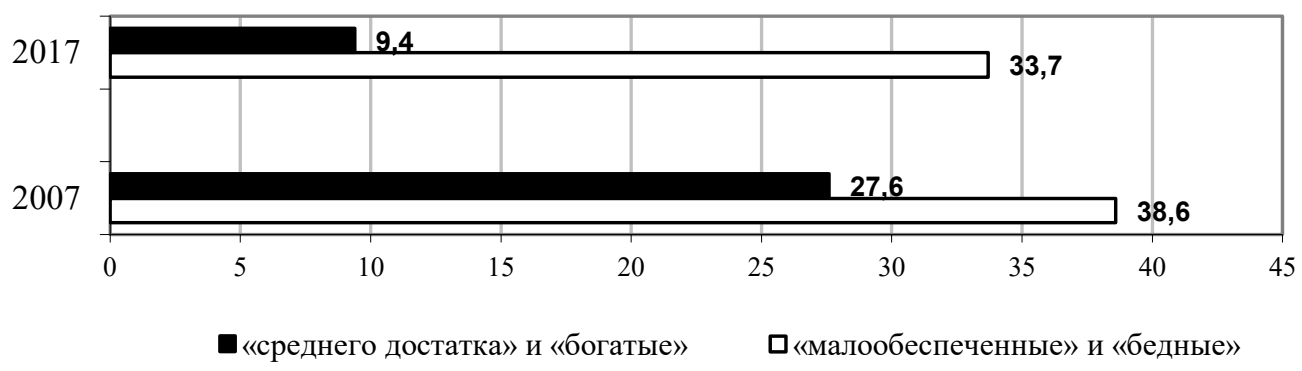

Puc. 2. Потенциал протеста в зависимости от социальной самоидентификации населения (доля «протестующих» от количества респондентов каждой категории,\%) Составлено автором по результатам проведенного исследования и исследования 2007 г. [2] 
9,4\% - в 2017 г. (рисунок 2).

Снижение протестных настроений среди различных категорий населения во многом обуславливается улучшением социального самочувствия населения в связи с мероприятиями властей по увеличению заработной платы, пенсий, социальных пособий работникам бюджетной сферы.

По сравнению с 2007 г. доля представителей «группы протеста» сократилась среди лиц, позитивно оценивающих свое эмоциональное состояние, с 32,1\% до 29,2\% - в 2017 г. А в группе жителей республики, испытывающих негативные эмоции, склонность к проявлению протестных настроений существенно не изменилась (35,3\% в 2017 г. против 34,8\% - в 2007 г.) (рисунок 3).

В 2017 г. доля представителей «протестной группы» осталась на прежнем уровне среди жителей региона, позитивно оценивающих курс экономических реформ, проводимых Президентом РФ (с 26,5\% в 2007 г. до 25,8\% в 2017 г.). Среди населения, неодобрительно характеризующего экономическую политику Главы государства и среди тех, кто относится к ней нейтрально, доля «протестующих» не изменилась - с 34,3\% в 2007 г. до 35,6\% в 2017 г. и с 32,6\% в 2007 г. до 33,8\% в 2017 г. (рисунок 4).

В 2017 г. склонность к протесту заметно сократилась среди жителей региона как «полностью и в основном одобряющих деятельность» (с 35,4\% в 2007 г. до 11,7\% в 2017.), так и «полностью и в основном не одобряющих» Главы Дагестана (в 2007 г. - Президента Республики Дагестан) (с 33,9\% до 62,1\%, соответственно). Доля «протестующих» значительно сократилась, среди тех, кто с «деятельностью не знаком» и «затруднился ответить» с 30,7\% - в 2007 г. до 26,2\% в 2017 г. (рисунок 5).

За рассматриваемый период уменьшилось число склонных к протесту среди респондентов, расценивающих политическую обстановку в регионе в целом как «благополучную» и «положительную» с 35,1\% - в 2007 г. до 18,4\% в 2017 г. В группе населения оценивающих политическую ситуацию как «напряженная, критическая и взрывоопасная», существенно возросла доля протестующих с 29,1\% до 42,9\% в 2017 г. (рисуНок 6).

Доля «протестующих» среди тех, кто считает, что Республику Дагестан ожидает «улучшение

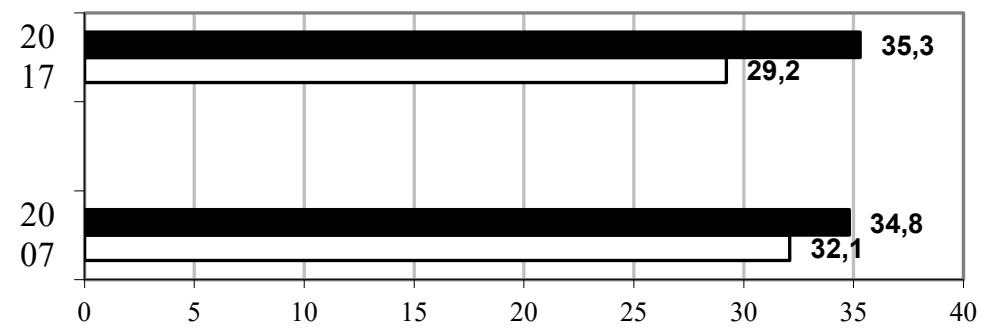

- Испытываю напряжение, раздражение, страх, тоску

口Прекрасное настроение, нормальное, ровное состояние

Puc. 3. Потенциал протеста в зависимости от оценок социального настроения (доля «протестующих» от общего количества респондентов каждой категории,\%) Составлено автором по результатам проведенного исследования и исследования 2007 г. [2]

2017

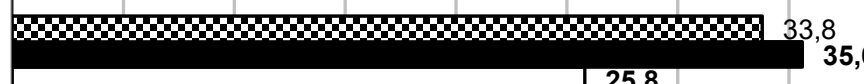

2007

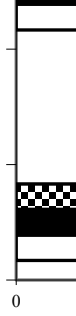

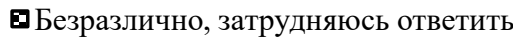 \\ В основном отрицательно \\ 口В основном положительно
}

Puc. 4. Уровень потенциала протеста в зависимости от оценок курса экономических реформ, проводимых Президентом РФ (доля «протестующих» от общего количества респондентов каждой категории, в\%)

Составлено автором по результатам проведенного исследования и исследования 2007 г. [2] 


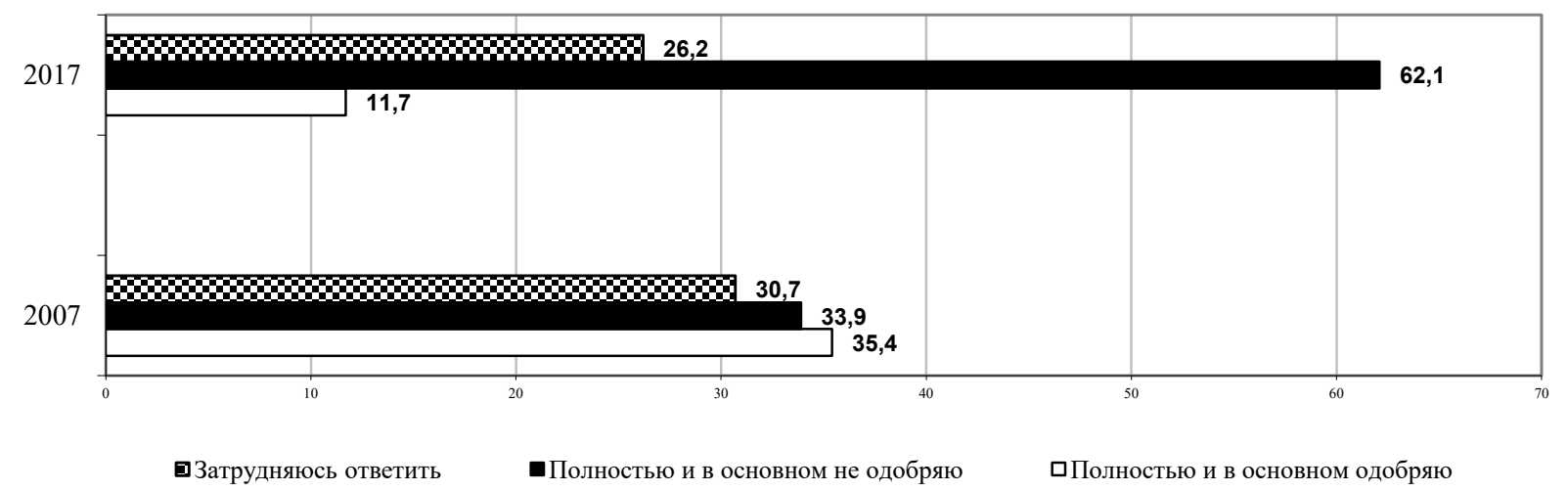

Puc. 5. Уровень потенциала протеста в зависимости от оценок деятельности Главы РД (2017 г.) и Президента РД (2007 г.) (доля «протестующих» от общего количества респондентов каждой категории, в\%)

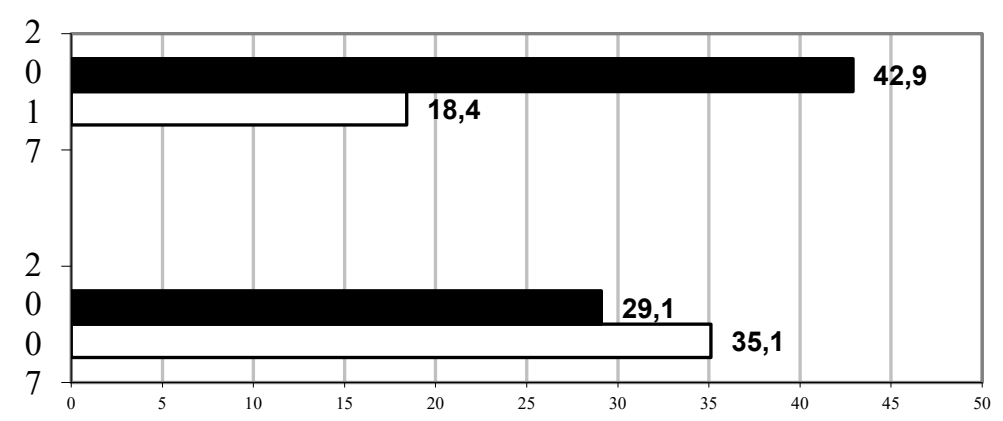

\author{
«Напряженная», \\ «критическая, \\ взрывоопасная» \\ 口«Благополучная», \\ «положительная»
}

Puc. 6. Уровень потенциала протеста в зависимости от оценок политической ситуации в регионе (доля «протестующих» от общего количества респондентов каждой категории, в\%)

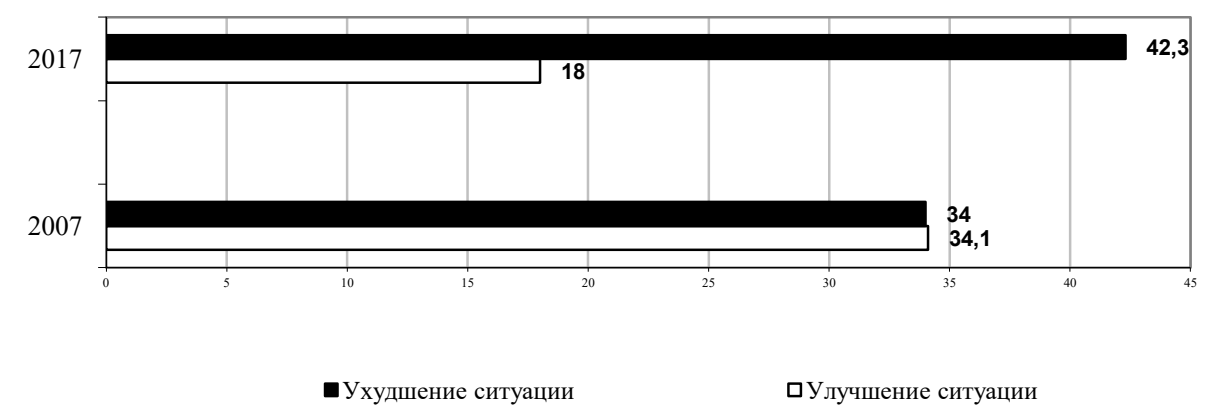

Puc. 7. Уровень потенциала протеста в зависимости от оценок перспектив политической жизни региона (доля «протестующих» от общего количества респондентов каждой категории, в\%)

ситуации» в ближайшее время в политической жизни снизилась с 34,1\% - в 2007 г. до 18,0\% - в 2017 г., а тех, кто считает, что республику ожидает «ухудшение ситуации» в политической жизни увеличилась с 34\% - в 2007 г. до 42,3\% - в 2017 г. (рисунок 7).

Кроме того, большинство респондентов (в среднем свыше 50\%, (в 2007 г. их доля составляла $-54,6 \%)$ считают, что спокойствие в регионе является большой ценностью, ради которой можно терпеть определенные материальные трудности. Следует отметить, что при явном доминировании причин, побуждающих к протесту, и серьезном ущемлении насущных жизненных интересов, большинство населения сохраняет здравый смысл и выдержку, которая позволяет Дагестану пережить трудный в социально-экономическом плане период развития экономики без массовых социальных взрывов.

Таким образом, протестный потенциал в 
Республике Дагестан с 2017 г.(15,3\%) хоть и снизился в сравнении с 2007 г (30,4\%), но по многим позициям обществом высказано крайне неодобрительное отношение ко всей социально-экономической ситуацией в регионе, к курсу проводимых экономических преобразований проводимой властью Республики Дагестан.

О своей готовности поддержать акции протеста в 2017 г. чаще других заявляли жители региона, отличающиеся негативными оценками своего экономического положения и социального самочувствия (около 30\%), а также неодобрительно оценивающие деятельность общественных структур и властей (свыше 35\%). Однако в сравнении с 2007 г. удельный вес «протестующих» в соответствующих категориях населения заметно сократился. Дальнейшие изменения протестных настроений в регионе будут зависеть от эффективности мероприятий властных структур различных уровней, направленных на улучшение социально-экономического положения населения.

Выводы. Достаточно очевидно, что ситуация в Республике Дагестан, далеко не радужная. И результаты проведенного обследования сви- детельствуют об обеспокоенности и недовольстве людей в целом социально-экономической ситуацией в регионе. Люди не готовы принимать участие в митингах и акциях протеста. Но если проанализировать ту часть населения, которая может принять участие в акциях протеста, то можно сказать, что здесь люди пойдут, и будут протестовать не против нынешней власти, а будут выступать против сложившейся социально-экономической ситуации. Поэтому можно сказать, что если акции протеста и будут иметь место, то это будут протесты, связанные с ухудшением социально-экономической ситуации в регионе.

Для своевременного выявления «проблемных точек» в социально-экономической региональной политике на ранних стадиях представляется целесообразным проведение независимых регулярных мониторингов. Результаты анализа данных таких мониторингов существенно повысят информативность и эффективность решений органов государственной власти, направленных на локализацию и устранение причин, способных послужить основанием для открытого протестного поведения населения.

\section{Библиографический список}

1. Регионы России. Социально-экономические показатели. 2017: Р32. Стат. сб. / Росстат. М., 2017. - 1402 с.

2. Хаджалова Х.М. Потенциал социального протеста в Республике Дагестан //Народонаселение. 2008 . № 1. C. $139-145$.

3. Хаджалова Х.М. Об измерении социальной напряженности (на материалах Республики Дагестан) // Труд и социальные отношения. 2008. № 7. С. 119-127.

4. Хаджалова Х.М. Основные направления повышения качества жизни населения и снижения социальной напряженности в Республике Дагестан // Региональная экономика: теория и практика. 2010. № 3. С. 35-38.

5. Хаджалова Х.М. Корреляционная зависимость качества жизни населения и социальной напряженности // Региональные проблемы преобразования экономики. 2012. № 2. С. 286-294. 